\title{
ФИМОАОГИЯ. АИТЕРАТУРОВЕДЕНИЕ
}

УДК $81.821 .512 .144+81.2$

DOI: $10.15350 / 26191490.2020 .2 .10$

Ю. В. Гориунов

\section{ЭТНОКУАЬТУРНЫЕ РЕАМИИ В ПОВЕСТИ “АЙБИКА" БАШКИРСКОЙ ПИСАТЕАЬНИЦЫ ХАДИИ ДАВАЕТШИНОЙ}

\begin{abstract}
В статье представлен адекватный социокультурный и лингвокультурологический комментарий обозначениям специфических элементов быта и культуры, значимых для башкирского народа, на основе русского перевода текста повести «Айбика» Хадии Давлетшиной. Они квалифицируются как культуронимы, которые для башкирской лингвокультуры являются идионимами (естественными элементами «своей», внутренней культуры), а в рамках русского языка и лингвокультуры - ксенонимами (обозначениями элементов иноязычной культуры). Основной метод исследования - описательный, реализованный в приемах систематизации, обобщения и интерпретации языкового материала. Лингвистические методы включают контекстный анализ и метод семантической интерпретации. Из 30 лексических этнокультуронимов, отобранных из повести «Айбика», 15 проанализированы и снабжены социокультурным комментарием, 4 башкирские пословицы - лингвокульурологическим и социокультурным комментарием.
\end{abstract}

Ключевые слова: Хадия Давлетшина, повесть «Айбика», историзм, культуроним, экзотизм, этнографизм, этнокультурная реалия, пословицы, поговорки.

В ряду башкирских писательниц имя Хадии Лутфулловны Давлетшиной (1905-1954) стоит одним из первых. Ее самое значительное произведение - монументальный эпический роман «Иргиз», за который автор посмертно удостоена самой первой Республиканской премии им. Салавата Юлаева 1967 г. Творчество писательницы повлияло на развитие жанра романа башкирской литературы, она сказала здесь новое слово и при этом оставила ярчайший след в национальной прозе.

Первым значительным произведением, которое вышло в свет в 1931 г. и принесло писательнице широкую известность, была повесть «Айбика», посвященная судьбе молодой женщины-башкирки. В 1936 г. повесть «Айбика» была переведена на русский язык. Описание жизни героини разворачивается на фоне исторических событий в Башкирии в годы империалистической и гражданской войн и в период индустриализации. Повесть, таким образом, отсылает читателя в далекое советское прошлое столетней давности и, как следствие, содержит реалии-историзмы, советизмы, а также этнографизмы, экзотизмы, тюркизмы и арабизмы, которые могут озадачить современного читателя как оригинала, так и русскоязычной версии, и оказаться не понятными читателю-иностранцу, если он не имеет представления об образе жизни в советской России в 20-30 гг. прошлого века.

Повесть «Айбика» содержит ценную культуроносную информацию, касающуюся традиционных форм народного быта и культуры, обычаев и традиций, позволяет проследить как меняются формы хозяйствования и вместе с этим менталитет крестьян-башкир, почувствовать дыхание времени. Она насыщена лексикой, включающей понятия «историзм», «советизм», «культуроним» и «экзотизм».

Цель статьи - рассмотреть и дать адекватный социокультурный комментарий обозначениям специфических элементов быта и культуры, значи- 
мых для башкирского народа, на основе русского перевода текста повести «Айбика» Хадии Давлетшиной (перевел с башкирского Рим Ахмедов). Они квалифицируются как культуронимы, которые для башкирской лингвокультуры являются идионимами (естественными элементами «своей», внутренней культуры), а в рамках русского языка и лингвокультуры - ксенонимами (обозначениями элементов иноязычной культуры).

Обращение к теме вызвано настоятельной необходимостью систематизировать фрагменты культурного опыта башкирского народа, дать им адекватное социокультурное описание.

В центре повести образ женщины-башкирки Айбики, которая, под влиянием исторических перемен, прошла трудный путь становления и роста самосознания. Испытав много нужды и лишений, она сохранила чувство собственного достоинства, стала одной из первых женщин в ауле, научившихся грамоте, закончила курсы трактористов, стала передовой колхозницей. Айбика всем сердцем поддержала новую власть, видя в ней спасение от нищеты и угнетения. Впервые в башкирской литературе глубоко и обстоятельно был показан процесс становления личности простой женщины-башкирки в условиях советской власти, давшей ей возможности, которых не было в прежнее время.

Мы знакомимся с Айбикой в трудный момент жизни, когда, оставшись одна без мужа и похоронив его родителей в голодный год, она вынуждена была батрачить у деревенского бая Кутлуяра. Ему понадобился человек, который мог бы исправно вести домашние дела. Желающих было достаточно, но выбор бая пал на Айбику: ей можно было не платить; более того, в глазах деревенских он выглядел благодетелем, приютив бедную родственницу, ведь Айбика приходилась ему снохой старшего брата. Молодая женщина вынуждена была согласиться от безвыходности. У Кутлуяра Айбике приходилось не сладко: изматывала бесконечная грубая работа с рассвета и до темноты, за которую ей не платили, ранили душу несправедливые попреки и издевки. Каждый вечер она буквально валилась с ног от усталости: в хозяйстве Кутлуяра она доила коров и кобылиц, носила воду, гоняла овец, коз и коров в стадо и домой с пастбища, топила печь, ставила самовар, готовила еду для косарей и для семьи Кутлуяра, чистила до блеска медные тазы и казан, прислуживала за столом, а у самой даже не было времени поесть.
Из забитой, боязливой и робкой батрачки, вступив в колхоз, получив профессиональную подготовку, закончив курсы трактористов, Айбика со временем приобрела уверенность в себе и в выбранном пути, приняла идеи социализма, стала активным борцом за его строительство. Она нашла в себе силы простить Юлдыбая. Взяв слово в прениях по докладу Юлдыбая на первом совещании колхозниц, она выступила с инициативой и обращением к женщинам-колхозницам передать свои украшения, лежащие в сундуках, в задаток за трактора и другую сельхозтехнику, которые приходилось дорого покупать за границей. Айбика вызвала восхищение Юлдыбая, которому казалось, что вся она - воплощение женской силы, крепости и уверенности, и даже ее не по моде длинное и широкое платье, обыкновенная шерстяная шаль, которую она держала в руках, служили предметами, как бы подчеркивающими эту силу. Юлдыбай любовался ею и задавался вопросом, когда она всему этому научилась и откуда у нее взялись бойкость и уверенность.

Повесть завершается оптимистичной картиной весеннего сева. Айбика за рулем трактора «Интернационал» вся устремленная вперед, нажимала на послушные рычаги, оставляя за собой ровную, прямую борозду.

Поскольку анализируется повесть в ее переводной версии на русском языке, то оценивается текст и лексика с позиций русского языка как языка-рецептора и языка перевода, для которого многие слова в переводе с башкирского воспринимаются как экзотизмы и этнографизмы, символизирующие чужую культуру. Экзотизмы (иначе экзотическая лексика) определяются как слова и выражения, заимствованные из других языков, часто малоизвестных, для придания речи особого (местного) колорита (бай, бек, бешмет, гяур, делибаш, зурна, паранджа, пиала, чайхана, яныччар) [Розенталь, 1976, с. 533]. То есть это иноязычные слова или выражения, обозначающие незнакомую вещь или понятие, свойственные материальной и духовной культуре другого народа (и употребляемые для придания речи особого, местного, регионального или этнического колорита). К экзотизмам принято относить национальные названия предметов быта, домашней утвари, одежды и обуви, кушаний и напитков, обычаев, обрядов, праздников и т. д. того или иного народа, той или иной страны. 
Ключевыми для понимания феномена экзотизмов выступают термины «безэквивалентный» и «лакунарный», указывающие на то, что для экзотизмов (в русском языке) не существует аналогов или наименований-синонимов, поскольку в принимающей культуре отсутствуют те предметы, процессы, явления и т. д., которые этими словами называются, следовательно в языке-рецепторе нет и соответствующего обозначения. Являясь лексикой лакунарной, экзотическая лексика требует альтернативного подхода к переводу. Отметим, что в межкультурной коммуникации для обозначения элементов иноязычных культур наряду с термином «экзотизм» используется конкурирующий термин «ксеноним» [Кабакчи, 2001; Кабакчи, 2002].

Значительный пласт культуронимов представлен лексикой, относящейся к тематическим полям «одежда и обувь (включая аксессуары и украшения)», «башкирская кухня», «убранство башкирского дома», представляющими материальную культуру, «семейно-брачные отношения» как принадлежность культуры материально-духовной, «термины и формы обращения», «башкирские пословицы и поговорки» как принадлежность духовной культуры.

Сцена замужества Айбики дает возможность обратиться к характеристике некоторых обозначений специфических элементов быта и культуры башкир.

Айбику рано выдали замуж (ей шел 15 год), не спросив согласия (у татар и башкир согласие молодых было не обязательным). Сваты долго торговаться не стали, дали шестнадцать рублей магара - выкупа за невесту. К свадьбе зарезали барана. Мулла совершил никах - скрепил молитвой брак. Мать повесила полог, за которым посадили Айбику. Приехавшая на свадьбу свекровь вошла за полог, пожелала Айбике счастья и дала традиционные наставления, одно из которых касалось отношений в семье: «Желтым скрипнув сапожком и не спрятавши лица, по соседкам не ходи, сор из дому не неси!» [Давлетшина, 1984, c. 17-18]. Так Айбика уехала снохой в аул, что в восемнадцати верстах от родного дома. Провожая, одели ее в красное сатиновое платье, плисовый казакей и новые сапожки. На грудь повесили хакал, который мать начала делать еще в ту пору, когда Айбика была совсем маленькой. Голову повязали цветистым кашемировым платком.
Приданого за ней не было. Мать, не придумав ничего лучшего, вынесла и положила в телегу стеганое лоскутное одеяло и одну из двух своих больших подушек [Давлетшина, 1984, с. 19]. В ушах Айбики продолжали звучать напутственные слова матери: «Несчастная ты моя доченька! Не смогла я тебя проводить, как положено, повесив сельтяр, надев кашмау, накинув елян. Не подняла красный полог, не погнала за тобой стадо овец. Пусть тебе теперь откроется счастье, ласточка моя!» [Давлетшина, 1984, с. 19-20]. Теперь уж ей не ходить простоволосой, как было в девичестве, а если ненароком покажешься на дворе в неправильно повязанном платке, то по всей деревне об этом заговорят. Поэтому отныне с умом надо делать каждый шаг, продумать каждое слово, прежде чем произнести, разговаривать тихо, громко не смеяться [Давлетшина, 1984, с. 21].

Для читателя русскоязычной версии повести для понимания культурных символов сделаны постраничные пояснительные сноски к словам хакал (женское нагрудное украшение из серебряных монет), сельтяр (богатый нагрудник из монет и кораллов), кашмау (старинный головной убор замужних женщин), елян (верхняя одежда в виде халата без воротника). Слово магар пояснено в тексте. Религиозные термины мулла и никах, по мнению редактора, в комментариях не нуждаются. Из выделенных нами слов в данном контексте недостаточно ясен ксеноним казакей. Он пояснялся ранее (казакей - национальная одежда, род полукафтана на подкладке длиной выше колен, с рукавами до локтя и стоячим воротником) и потому в данном контексте подается уже без толкований. К этому добавим, что казакей или кэзэки один из особенных нарядов башкир - верхняя одежда, представляющая собой расклешенный кафтан с воротником-стойкой и глухой застежкой на пуговицах, уникальность которого в том, что его носили и мужчины, и женщины.

Приведенные отрывки содержат также указания на поведение башкирской женщины за пределами дома и в присутствии мужчины: нельзя замужней женщине ходить простоволосой, нельзя открывать лицо, разговаривать следует тихо, громко не смеяться. В детстве мать поучала Айбику: «Нехорошо открывать лицо перед чужим мужчиной. Это грех. А когда мужчина идет, женщина не должна переходить перед ним дорогу» [Давлетшина, 1984, с. 12]. Подобными наставлениями 
и заканчивалось воспитание маленькой дочери. Ей внушали страх перед нечистой силой, пугали возмездием за совершенные и за будущие грехи, прививали беспрекословное послушание старшим.

Во многом кодекс поведения диктуется религиозным воспитанием, которое получали девочки в то время. Айбика имела минимальное образование: ее, как и других деревенских детишек, три зимы учила грамоте жена муллы. Отец посчитал, что, знания имана, необходимого для намаза и почерпнутое из нескольких глав молитвенника, вполне достаточно для девушки. Религиозная лексика по численности оказалась в нашей выборке самой представительной. Некоторые специфические термины снабжены постраничными сносками-пояснениями, например, молитвенник и его главы (иман-иарты - учебник для религиозных школ; абжат, калиматен - названия глав из молитвенника иман-шарты), муэдзин - служитель мечети, остабика - жена муллы или муэдзина. Другие термины религии переводчик и редактор посчитали не нуждающимися в пояснении. К таковым отнесены, в частности, иман, мулла, намаз, никах. Два из них - мулла и намаз отражены в авторитетных словарях русского языка и толковом словаре иноязычных слов: мулла - служитель религиозного культа у мусульман [Крысин, 2002, с. 457], служитель культа у мусульман [Ожегов, 1984, с. 313]. Намазу мусульман: совершаемая в определенное время дня молитва, состоящая в чтении отрывков из Корана, которой предшествует омовение [Крысин, 2002 , с. 463]; молитва из стихов корана у мусульман [Ожегов, 1984, с. 328]. Полагаем, что слова иман и никах могут входить в тезаурус и культурный фон русскоязычных читателей, проживающих в Татарстане и Башкортостане, т. к. титульные нации исповедуют ислам. Однако за пределами этих республик читательская аудитория может их и не знать. Поэтому считаем нужным дать пояснения. Слово «никах» - арабское слово, означающее «брак». Никах считается религиозной церемонией, при которой жених и невеста соглашаются стать мужем и женой (атрибутом никаха считается молитва, прочитанная муллой и скрепляющая брак). Никах - равноправный брак, заключаемый между мужчиной и женщиной. Nikah заимствовано английским языком и считается неологизмом [Горшунов, 2015; Горшунов, 2018]. Понятие имана является одним из ключевых и спорных в исламе. Термин «иман» в значении веры употребляется в Коране более сорока раз и трактуется весьма широко как вера в истинность ислама; вера в Аллаха, ангелов, Священные Писания, пророков, Судный день, в воздаяние за добро и зло.

Обратимся теперь к пословицам и поговоркам, которые в лингвострановедении и межкультурной коммуникации принято относить к афористическому уровню [Томахин, 1988].

Паремии (пословицы и поговорки) представляют собой коммуникативные единицы, образно, зримо, сжато и емко выражающие народную мудрость и характеризующиеся воспроизводимостью в речи в готовом виде. Передаваясь из поколения в поколение, они выступают хранилищем культурного наследия своего создателя - народа, отражая специфические особенности многосторонней материальной и духовной культуры, национальный менталитет, особое видение мира [Нуриахметов, 2001].

Являясь метким образным изречением, они обобщают и типизируют различные явления жизни. Пословицы - краткие меткие высказывания, в которых говорится одно, а подразумевается другое, содержится намек нравоучительного и/или назидательного характера. Иными словами, пословицы имеют прямой и переносный смысл (мораль). Считается, что пословицы отличаются от поговорок более высоким обобщающим смыслом.

В небольшой по объему повести «Айбика» Хадии Давлетшиной мы встретили около десятка назидательных пословиц, передающих народную мудрость. Впечатляют пословицы, выражающие суждение об уме человека. Так, во время полемики между баем Кутлуяром и его соседом Суяргулом, возникшей в связи с намерением Суяргула вступить в колхоз, недовольный Кутлуяр увещевает соседа: «Но как мог попасть в волчью стаю ты, почтенный Суяргул, уважаемый всеми хозяин? Лишь потому, что твой мальчишка комсомольцем стал? Только дурной конь за стригунком увязывается. У тебя же, благодарение аллаху, есть достаток» [Давлетшина, 1984, c. 41-42].

Считается, что человек становится мудрым благодаря жизненному опыту и что чем старше человек, тем он мудрее. Наличие ума и знаний является достоинством [Гатауллина, 2011]. Кутлуяр сравнивает почтенного Суяргула со стригунком годовалым жеребенком, которому обычно подстригают гриву, упрекает его в том, что он поддался влиянию сына-комсомольца, что он ведет себя неразумно. В русской лингвокультуре в ситуации, 
когда человек в возрасте ведет себя неразумно, поступает как молодой и неопытный человек, употребительна пословица «Достиг возраста быка, а ум меньше, чем у теленка». О пожилом человеке недалекого ума также говорят: «Волос длинный, ум короткий», «На голове густо, а в голове пусто».

На обидные слова бая Суяргул отвечает: «Ты назвал меня дурным конем. Старики говорят: ум не в возрасте, а в голове. Вот и сын мой, хотя и молод, раскрыл глаза мне, старику» [Давлетшина, 1984, с. 42]. Действительно, величие от ума, а не от возраста. Далее Суяргул добавляет: «Есть еще поговорка: голый воды не боится», смысл которой, как нам представляется, в том, как голому человеку одежды не замочить, так и бедняку нечего терять, обеднеть не страшно. Как говорят, чему бывать, тому не миновать. Голый - что святой: не боится беды.

Отметим еще одну пословицу: лучше горькая правда, чем сладкая ложь. Она прозвучала в речи Таймаса, друга детства Юлдыбая, который видит, что его земляк и давний друг обуржуазился, поддался влиянию своей расчетливой жены: «Есть пословица: лучше горькая правда, чем сладкая ложь. Скажу тебе прямо - пропала твоя голова». «Почему?» залился краской Юлдыбай, прекрасно понимая, о чем идет речь [Давлетшина, 1984, с. 51]. Ср. русскую пословицу: Хлеб-соль ешь, а правду режь.

Подводя итог, мы можем констатировать, что, если рассматривать пословицу как популярное краткое изречение со словами совета или предупреждения, насыщенное дидактическим содержанием, то представленные нами башкирские пословицы об интеллектуальных чертах человека (об уме) и об отношении к имуществу, богатству, истине содержат следующие мудрые мысли (закономерности): ум - величина относительная, человек становится мудрым благодаря жизненному опыту, старый человек - человек мудрый, хотя бывают

\section{ИСТОЧНИКИ И ЛИТЕРАТУРА}

Гатауллина, 2011 - Гатауллина Л. М., Горшунов Ю. В. Английские пословицы, отражающие интеллектуальные черты человека // Структурно-семантические, когнитивные, прагматические и другие аспекты исследования единиц разных уровней. Современные проблемы лингводидактики / Под общ. ред. Ю. В. Горшунова. Бирск: Бирск. гос. соц-пед. акад., 2011. Вып. 7. С. 37-41. исключения. Всегда следует говорить правду человеку, даже если она обидна и задевает за живое.

Ценность пословиц определяется многообразием сведений, которые в них содержатся, их назидательным характером. Они передают выраженную в них в сжатой и образной форме народную мудрость, многовековой жизненный опыт народа, учат отличать добро от зла, правильно оценивать явления жизни.

Из 30 лексических этнокультуронимов, отобранных нами из повести «Айбика», в статье были проанализированы и снабжены социокультурным комментарием 15, из 10 пословиц и поговорок, принадлежащих афористическому уровню, прокомментированы 4.

Хотя повесть «Айбика» небольшого объема (порядка 80 страниц), она является ценным источником социокультурной информации. Некоторые из башкирских культуронимов, встретившихся на страницах повести, стали более или менее известными, получили фиксацию в толковых или иных словарях, т. е. стали словарными ксенонимами и должны быть квалифицированы как базовые (например, аул, коран, мулла, намаз). Они вряд ли нуждаются в пояснении в отличие от малоизвестных ксенонимов. Умение дать нужное, предельно краткое и вместе с тем доступное адресату пояснение - важная часть межкультурной коммуникации, особенно это касается передачи культуронимов на иностранных языках, например, английском [Горшунов, 2020], что открывает новый перспективный вектор исследования башкирских культуронимов. Добавим к сказанному, что знание пословиц и поговорок того или иного народа способствует не только лучшему знанию языка, но и лучшему пониманию образа мыслей и характера народа. В этом заключается большая познавательная и воспитательная роль паремий в педагогическом процессе. Неисчерпаем их образовательный и воспитательный потенциал.

\section{REFRENCES}

Gataullina, 2011 - Gataullina L. M., Gorshunov Yu. V. Angliyskiye poslovitsy, otrazhayushchiye intellektual'nyye cherty cheloveka // Strukturno-semanticheskiye, kognitivnyye, pragmaticheskiye i drugiye aspekty issledovaniya yedinits raznykh urovney. Sovremennyye problemy lingvodidaktiki / Pod obshch. red. Yu. V. Gorshunova. Birsk: Birsk. gos. sots-ped. akad., 2011. Vyp. 7. C. 37-41. 
Гориунов, 2015 - Горшунов Ю. В. Новые арабские заимствования в английском языке из сферы религии // Структурно-семантические, когнитивные, прагматические и другие аспекты исследования единиц разных уровней. Современные проблемы лингводидактики. Вып. 15. Бирск: Бирский филиал БашГУ, 2015. С. 34-42.

Горшунов, 2018 - Горшунов Ю. В. Арабский след в английском языке // Вестник Башкирского университета. 2018. Т. 23. № 2. С. 451-456.

Горшунов, 2020 - Горшунов Ю. В. Трудности и способы перевода прозы Х. Давлетшиной на английский язык // Материалы международной научно-практической конференции, посвященной 115-летию со дня рождения Х. Давлетшиной. Том. Выпуск VII. Сер. Давлетшинские чтения. Бирск, 2020. С. 5-9.

Давлетшина, 1984 - Давлетшина Хадия. Айбика. Повесть. Уфа: Башкирское книжное издательство, 1984. $88 \mathrm{c}$.

Кабакчи, 2001 - Кабакчи В. В. Практика англоязычной межкультурной коммуникации. СПб.: Издательство «Союз», 2001. 480 с.

Кабакчи, 2002 - Кабакчи В. B. The Dictionary of RUSSIA (2500 cultural terms). Англо-английский словарь русской культурной терминологии. СПб.: Издательство «Союз», 2002. 576 с.

Крысин, 2002 - Крысин Л. П. Толковый словарь иноязычных слов. 4-е изд., стереотип. М.: Рус. яз, 2002. $856 \mathrm{c}$.

Нуриахметов, 2001 - Нуриахметов Г. М., Салин С. В. Язык и культура в пословицах и поговорках: Учебно-справочное пособие. Бирск: Бирск. гос. пед. ин-т, 2001. 146 с.

Ожегов, 1984 - Ожегов С. И. Словарь русского языка / Под ред. докт. филол. наук, проф. Н. Ю. Шведовой. 16-е изд., испр. М.: Рус. яз., 1984. 797 с.

Розенталь, 1976 - Розенталь Д. Э., Теленкова М. А. Словарь-справочник лингвистических терминов. Изд. 2., испр. и доп. М.: Просвещение, 1976.543 с.

Томахин, 1988 - Томахин Г.Д. Реалии-американизмы. Москва: Высш. шк., 1988. 239 с.
Gorshunov, 2015 - Gorshunov Yu. V. Novyye arabskiye zaimstvovaniya $\mathrm{v}$ angliyskom yazyke iz sfery religii // Strukturno-semanticheskiye, kognitivnyye, pragmaticheskiye i drugiye aspekty issledovaniya yedinits raznykh urovney. Sovremennyye problemy lingvodidaktiki. Vyp. 15. Birsk: Birskiy filial BashGU, 2015. S. 34-42.

Gorshunov, 2018 - Gorshunov Yu. V. Arabskiy sled $\mathrm{v}$ angliyskom yazyke // Vestnik Bashkirskogo universiteta. 2018. T. 23. №2. C. 451-456.

Gorshunov, 2020 - Gorshunov Yu. V. Trudnosti i sposoby perevoda prozy Kh. Davletshinoy na angliyskiy yazyk // Materialy mezhdunarodnoy nauchno-prakticheskoy konferentsii, posvyashchennoy 115-letiyu so dnya rozhdeniya Kh. Davletshinoy. Tom. Vypusk VII. Ser. Davletshinskiye chteniya. Birsk, 2020. S. 5-9.

Davletshina, 1984 - Davletshina Khadiya. Aybika. Povest'. Ufa, Bashkirskoye knizhnoye izdatel'stvo, 1984. $88 \mathrm{~s}$.

Kabakchi, 2001 - Kabakchi V. V. Praktika angloyazychnoy mezhkul'turnoy kommunikatsii. SPb.: Izdatel'stvo «Soyuz», 2001. 480 s.

Kabakchi, 2002 - Kabakchi V. V. The Dictionary of RUSSIA (2500 cultural terms). Anglo-angliyskiy slovar' russkoy kul'turnoy terminologii. SPb.: Izdatel'stvo «Soyuz», 2002. $576 \mathrm{~s}$.

Krysin, 2002 - Krysin L. P. Tolkovyy slovar' inoyazychnykh slov. 4-ye izd., stereotip. M.: Rus. yaz, 2002. $856 \mathrm{~s}$.

Nuriakhmetov, 2001 - Nuriakhmetov G. M., Salin S. V. Yazyk i kul'tura v poslovitsakh i pogovorkakh: Uchebno-spravochnoye posobiye. Birsk: Birsk. gos. ped. in-t, 2001. $146 \mathrm{~s}$.

Ozhegov, 1984 - Ozhegov S. I. Slovar' russkogo yazyka / Pod red. dokt. filol. nauk, prof. N. Yu. Shvedovoy. 16-ye izd., ispr. M.: Rus. yaz., 1984. 797 s.

Rozental', 1976 - Rozental' D. E., Telenkova M. A. Slovar'-spravochnik lingvisticheskikh terminov. Izd. 2., ispr. i dop. M.: Prosveshcheniye, 1976. 543 s.

Tomakhin, 1988 - Tomakhin G.D. Realii-amerikanizmy. Moskva: Vyssh. shk., 1988. 239 s.

Yu. V. Gorshunov

\section{ETHNOCULTURAL TERMS IN THE STORY «AYBIKA» BY KHADIYA DAVLETSHINA}

The article presents an adequate socio-cultural and linguocultural commentary on the designations of specific elements of everyday life and culture that are significant for the Bashkir people, based on the Russian translation of the story "Aibika" by Khadiya Davletshina. They are classified as cultural names, which for the Bashkir linguistic culture are 
idionyms (natural elements of "their own", internal culture), and within the framework of the Russian language and linguoculture, they are xenonyms (designations of elements of a foreign language culture). The main research method is descriptive, implemented in the methods of systematization, generalization and interpretation of linguistic material. Linguistic methods include the contextual analysis and method of semantic interpretation. Out of 30 ethnocultural names selected from the story "Aibika", we have analyzed 15 and provided them with sociocultural commentary. 4 Bashkir proverbs have been analyzed in social-and-cultural context.

Keywords: Khadia Davletshina, the story "Aibika”, historicism, culturonym, exoticism, ethnographism, ethnocultural reality, proverbs, sayings.

\section{Горшунов Юрий Владимирович,}

доктор филологических наук, профессор,

Башкирский государственный университет,

Бирский филиал,

(Бирск, Россия)

gorshunov_@rambler.ru
Gorshunov Yury Vladimirovich., Doctor of Philology, Professor, Bashkir State University,

Birsk branch

(Birsk, Russia)

gorshunov_@rambler.ru 